\title{
Optimal Design of Power Transformer with Advance Core Material using ANSYS Technique
}

\author{
Shabana Urooj, Tanya Singh, Mohammad Amir and Mohd Tariq
}

\begin{abstract}
Due to indulge behavior of core materials and losses that leads to degradation of transformer efficiency. This research paper evaluating the optimal performance of transformer with designing of a newly core material namely as $M_{0 . M e}{ }^{6}$. A possibility of increment in the efficiency for designed proposed model of transformer is observable. Also, a comparative analytical study based on the different designs of core type transformer with various core materials. The design and evaluation are performed on the Maxwell ANSYS electronic desktop platform, which provides an optimized design of transformer for practical applications. Whether it is a power transformer having lower frequency applications use in electronic circuits such as rectifying circuits or higher frequency applications power distribution circuit, etc. All transformer designs require performance evaluation in the working field and better efficiency to optimize the overall three-phase type core transformer. In this paper, proposed $\mathrm{Mo.Me}^{6}$ material with improved physical properties have been present of transformer efficiency and optimal design of core. The criteria include the changes in some effective parameters of the core, bringing out advancement in the working efficiency of the transformer. There is an opportunity to have a choice of desired material as designed particularly for the customer need making it will be more reliable and more suitable for various changeable conditions. For more efficient and effective working of transformer, this paper suggests core design with ANSYS techniques to achieve mentioned high efficiency with lower losses.
\end{abstract}

Index Terms - ANSYS (Analysis System), Mo.Me ${ }^{6}$ (Modified Material of Conductivity $10^{6} \mathrm{Sie} / \mathrm{m}$ ), Power Transformer.

\section{INTRODUCTION}

In today's world, electricity is one of the most vital components of modern society. The utility of transformers for power transmission was invented by Nikole Tesla in 19th century. From turning on a light bulb to running big factories every machine needs some source to work and the most needed source is electricity. Whether it is transmission or distribution, main component in electric power is transformer. The transformer had been playing an important role at various voltage levels for the interconnected power system [1]. At some frequency electrical power is transformed is one circuit to others by a static piece of equipment recognized as transformer [2]. In transformer, electrical energy is being transferred by magnetic coupling

Published on October 30, 2020.

Shabana Urooj, Department of Electrical Engineering, College of Engineering, Princess Nourah Bint Abdulrahman University, Riyadh, Saudi Arabia.

(e-mail: shabanaurooj@ieee.org)

Tanya Singh, Department of Electrical Engineering, School of Engineering, Gautam Buddha University, Greater Noida, India.

(e-mail: tstanyasingh26@ gmail.com) from one to other systems in the circuit without any requirement of relative motion within the parts.

In the core of transformer, a time-variant magnetic flux can be created by the application of alternating voltage to one winding with the introduction of voltage in another winding, as per mutual induction law. Faraday introduced the principle of transformer in 1831. An ideal transformer having no losses means its windings are free from ohmic resistance as well as magnetic leakage is considered as ideal transformer [3]. However, practically losses occur in the transformer, as output obtained from the transformation is not as same as the input applied. The law of energy states that "energy cannot be created nor be destroyed but can be transferred from one phase to another" and in this transfer of energy, losses occur. From past it has been noticed that two types of transformers have been in application that is core type and shell type of transformer. Transformers used as power transformers are one of the major apparatus in the power system [4]. Medium and large power transformers are very important and vital component of electric power systems [5]. Generally, power transformers are significant power devices where electromagnetic phenomena should subsist the severe short circuit current situations [6]. Distribution power transformers are also vital equipment of the distribution system, for transfer the electric power by step-up/down voltages in suitability with power distribution system to power consumers or power industry [7].

The condition monitoring of power transformers is of excessive importance while considering the consistency and safety perspective in a dynamic system. Nowadays the research on motoring of transformers is taking a great phase as many sensors are used in this method to check the working of transformer components, which can be core/winding type. Earlier in 2017, S. Anoop and N. Aufal [8] had proposed criteria for the selection of sensors that are used in advance monitoring systems of the transformer's winding. Like that the core monitoring system control system can be developed. A power transformer fault can lead to severe damage to the whole system itself and its surroundings. As the increasing concern on the transformer, recently in 2018 S. Kittan [9] did research leading to a discussion about actual $\mathrm{HI}$ (Health Index) methods through study. After that, the selection of a better method has been considered for the transformer. In this research paper a new material has been designed which led to

Mohammad Amir, Department of Electrical Engineering, Madan Mohan Malaviya University of Technology (MMMUT), Gorakhpur, India. (corresponding e-mail: md.amir@ieee.org)

Mohd Tariq, Department of Electrical Engineering, ZHCET, Aligarh Muslim University, Aligarh, India.

(e-mail: tariq.ee@ zhcet.ac.in). 
change in the working efficiency of the designed transformer. Similarly, new techniques and methods are designed to check the working of upcoming new core material.

In 2019, F. R. Ismagilov [10] developed a core material of amorphous magnetic material as a new material for the core. Here the authors have developed the new transformer rectifier unit. Here amorphous is used in transformer core material to improve efficiency. The losses are the main factor also in transformer owning cost [11]. The stability and reliability of the power transformers in power system applications mainly depends on the quality of employed ferrite cores [12]. Here, transformer core plays an important role in the working efficiency of transformer. New designing of core material has added an advantage of analyzing the working efficiency of transformer. Although the efficiency of power transformers for high-power convention, there are substantial quantities of power losses, that radiates heat inadequately into the ambient air [13], [14].

Improvement in the efficiency of transformer can be done by deducing electrical losses $\left(\mathrm{P}^{\mathrm{T}}\right)$ comprising of both core $\left(\mathrm{P}^{\mathrm{CORE}}\right)$ and copper losses $\left(\mathrm{P}^{\mathrm{CU}}\right)$ presenting in the following equation.

$$
\begin{gathered}
P^{T}=P^{C O R E}+P^{C U} \\
\text { Efficiency }(\mathrm{\eta})=\frac{\text { Output }}{\text { Input }+P^{T}} \times 100 \%
\end{gathered}
$$

In our proposed methodology, we are focusing on the losses occurring in the core which have to be minimized for improving three phase core type transformers. The reason is that while designing transformers main consideration should be focused on core losses as it comprises $70 \%$ of total losses in the transformer [15]. In this paper for the designing and comparison, purpose ANSYS electronics desktop software has been used. This software is a global platform, which provides opportunity for the simulation of various power system, power electronics components for the field of electrical engineers [16]. The whole simulation has been performed in $3 \mathrm{D}$. The reason is that most parameters directly affects the performances of transformer that can be seen in the 3D simulation [17]. Generally, inner structure parts of the transformer analysis are unpredictable and based on the electric field distribution in inner structure transformer [18] only specify 2D models. Therefore, these are the reasons why simulation is better in 3D rather than 2D simulation.

Section II of the manuscript contains the beginning of the idea with thoughtful procedure of introduction followed with explanation of methodology and the proposed model with material description of the completely generalized system with its parameters. Section III, this section presents the outcome of the results in a tabular manner with different results applied for the various designs simulated in the software. Last section includes conclusion, also presents the material optimization for future scope and the research work can be achieved further based on feasibility.

\section{DESCRIPTION OF PROPOSED SYSTEM}

\section{A. Material Design for Power Transformers}

The transformer designed in the software is a core type of transformer in which windings are wounded around all cores of the transformer. The following is the design of the proposed model.

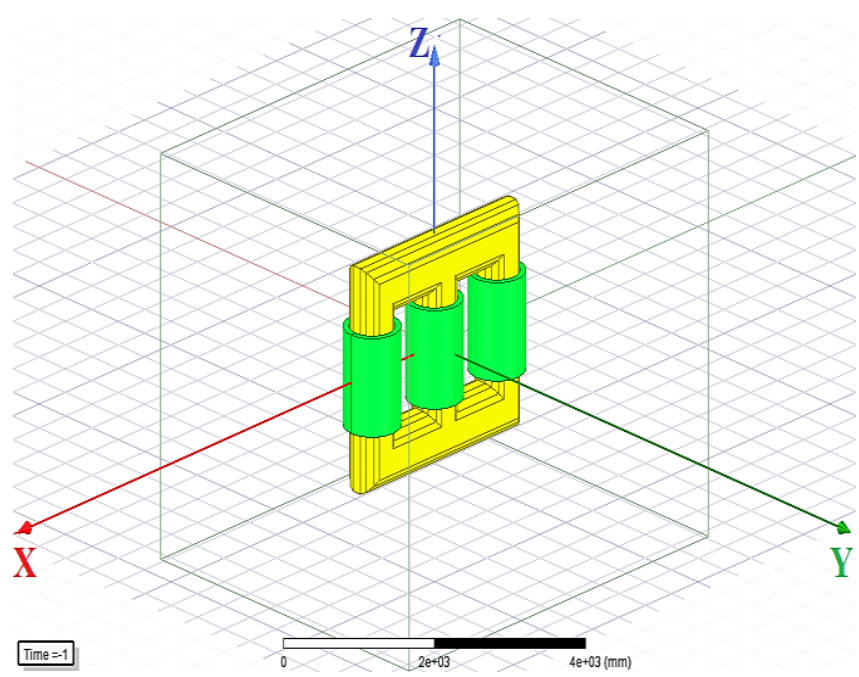

Fig. 1. Proposed model of the core type transformer designed in ANSYS.

Here, in the given Fig. 1, the transformer is a three-phase model which works in transient system. The voltage phases are cosine in nature. This figure depicts all three axis and dimensions $\mathrm{x}, \mathrm{y}$ and $\mathrm{z}$. The excitation in windings is applied in $\mathrm{x}-\mathrm{z}$ direction. The yellow color symbolizes the core, and the green ones are windings wounded on the core of the following are the system terminologies used:

a) Region: It is the confined box which is designed in all three dimensions. It is used to provide an environment for the transformer to work desired medium. (value used region: 40 , 250 and 40).

b) Transient system: The transient system has been taken to ensure the working of the transformer with varying voltage in all three phases.

c) Coil terminal: The terminals of coil have been selected to provide excitation in the coil terminal.

d) Materials used: The material used for the following are given below:

- For core: The material used in the core of the proposed model of the transformer is based on the parameters taken with B-H curve and Core loss curve. Here the material is termed as Mo.Me . Also, iron has been used to compare the working of the transformer.

- For winding: The copper material has been selected here because it's a good material used in the winding section and has been in use for achieving better performance.

e) Standard parameters: The following are the parameters, which have been used in the designing of the core transformer.

- $\quad V^{\text {Peak }}$ : Peak voltage of the transformer.

- $\boldsymbol{R}$ : Resistance of the winding terminal.

- Rating: The values of rating are taken accordingly for different applications.

f) Conductivity: Conductivity is referred as to the degree 
at which in a material there is a cause of flow of current that is it conducts electricity [19]. It is the ratio of current density to the electric field, in. which there is a flow of current in the material. Here it is taken as $\left(\mathrm{e}^{6}\right)$ or $1000,000 \mathrm{Siemens} / \mathrm{m}$.

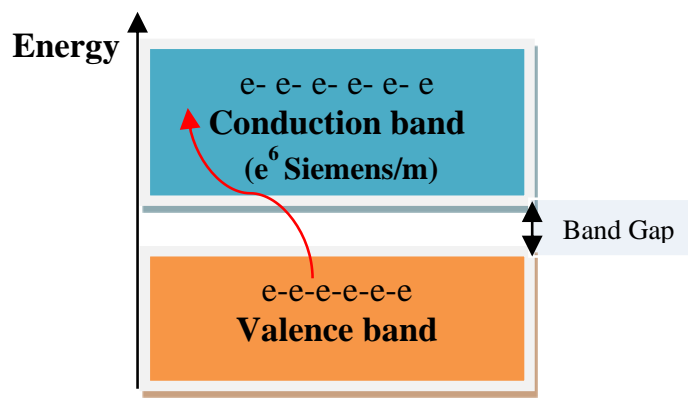

Fig. 2. Energy band diagram of Mo.Me .

The rise in the temperature of transformer is affected by the thermal resistance of transferring heat from conductor to ambient air, while for consideration of transformer design, material properties like dielectric and mechanical properties are placed on topmost priority. But here other parameters are considered as because electrical conductivity is playing an important role in the designing application.

g) Mass density: The mass density has been changed accordingly in the designing form based on requirements, where:

- Conductivity: 100,000 Siemens/m.

- B-H curve: for this curve, following conditions are there which are observable in Fig. 3,

$>$ If Yes: This means the B-H Curve is nonlinear.

$>$ If No: This means the curve is linear.

Where, magnetic flux density (B) is in tesla and $\mathrm{H}$ is in ampere/meter. The nonlinear curve shows that the material taken has nonlinear characteristics of which for every point the plot has been calculated.

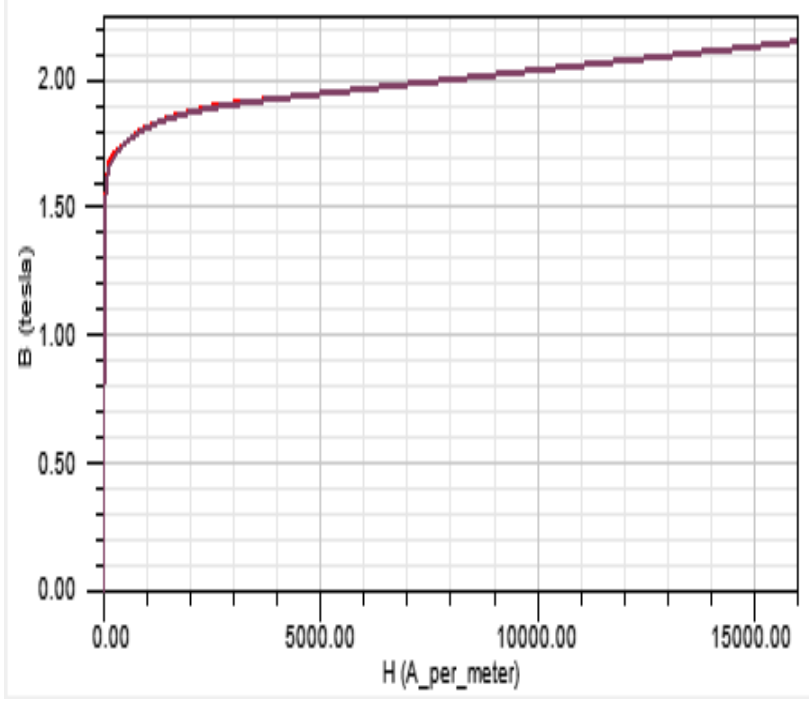

Fig. 3. Nonlinear B-H curve for iron material.

The distorting or harmonics observed in induced currents are also because of different changeable core material values for the transformer based on the B-H curve [20].

Core loss tab: This tab shows the graph obtained when standard parameters taken accordingly in the designing of core material [21]. Consideration of core loss unit is in $\mathrm{w} / \mathrm{kg}$. The designing and the process pattern of core loss curve has been explained in Fig. 4, by the flowchart.

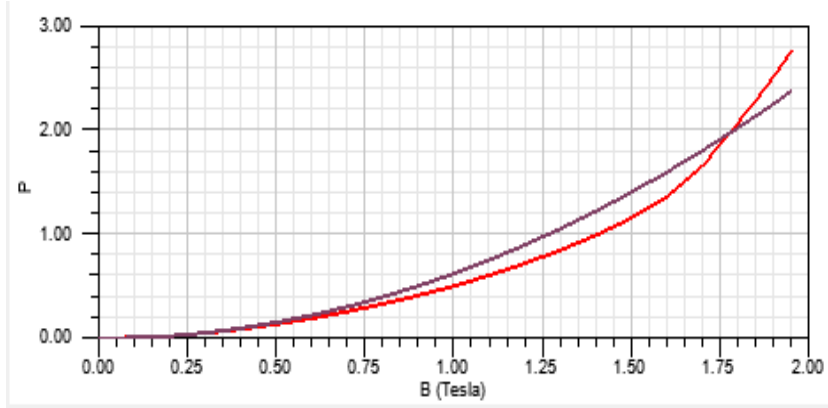

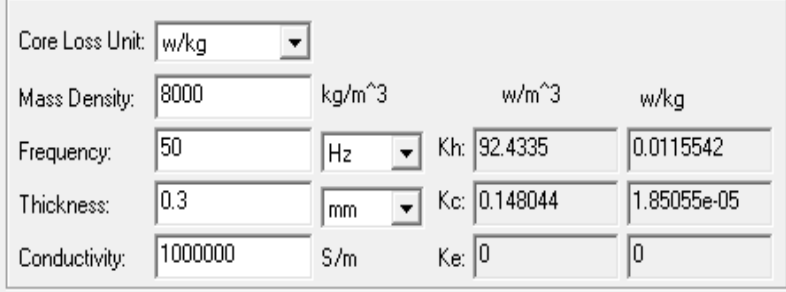

Fig. 4. Core loss tab curve of the core material.

Above Fig. 4, represents the curve between B (magnetic flux density) vs $\mathrm{P}$ (power of transformer). The red one shows the curve obtained from table in the given Fig. 4 . The blue line shows the variables which are dependent on the function of predictor that is showing the error term (which is the variable in a based statically data showing relationship between dependent variables and approximate variables), also it can be said that this line is showing the regression curve trace.

\section{h) Winding voltages:}

- For Phase I:

$$
V^{\text {Peak }} \cdot\left(1-\mathrm{e}^{(-60 \times \text { time })} \cdot \cos (2 . \pi .50 \times \text { time })\right.
$$

\section{- For Phase II:}

$$
\mathrm{V}^{\text {Peak }} \cdot\left(1-\mathrm{e}^{(-60 \times \text { time })}\right) \cdot \cos \left(2 . \pi .50 \times \text { time }+\frac{2}{3} \times \pi\right)
$$

\section{- For Phase III:}

$$
V^{\text {Peak }} \cdot\left(1-e^{(-60 \times t i m e)}\right) \cdot \cos \left(2 . \pi .50 \times t m e+\frac{4}{3} \times \pi\right)
$$

\section{i). Peak Voltage:}

$$
V^{\text {Peak }}=\text { Rating } \times \frac{\operatorname{Sqrt}(2)}{\operatorname{Sqrt}(3)}
$$

Table 1, showing the necessary parameters based on their outcome. Here, two types of input have been considered. That

\begin{tabular}{|c|c|c|c|}
\hline S. No. & Parameters & Table 3 & Table 4 \\
\hline 1 & Rating of Transformer & $20 \mathrm{KV}$ & $200 \mathrm{KV}$ \\
\hline 2 & Core material & Mo. $\mathrm{Me}^{6}$ and Iron & Mo.Me ${ }^{6}$ only \\
\hline 3 & Winding material & Copper & Copper \\
\hline 4 & Frequency & $50 \mathrm{~Hz}$ & $50 \mathrm{~Hz}$ \\
\hline
\end{tabular}
is for Table 3 instance 1, 2, 3, 4, 5 and 6 with $3 \Phi-20 \mathrm{KV}$ input has been used. While for Table 4 instance 7, 8, 9, 10 and 11 with $3 Ф-200 \mathrm{KV}$ input has been used.

There are some other parameters, which effects core loss selection curve of the core material like working life age of transformer is reduced by the harmonic distortion causing further heating in transformers parts and minimizing its 
appropriate operation [22]-[24]. These phenomena are demonstrated through flowchart in Fig.4 as follows:

- Stage 1: From starting the selection of core loss frequency the steps follows to selection of parameters.

- Stage 2: Then values of proposed model are selected. They can be based on the utility and working conditions.

- Stage 3: The graph automatically calculates the values of the mentioned error constants and curve of required core material is plotted.

- Stage 4: The selection of characteristics of B-H curve follows the selection of the behavior of core material.

- Stage 5: Hence, core material properties are defined significantly. In Fig. 3 and Fig. 4 both curves are given with their properties, which are depicted as in the Fig. 5. For the prevention of catastrophic failure or to minimize probability for unwanted outage.

Therefore, proper monitoring of transformers is very much essential with good and regular maintenance [25], [26].

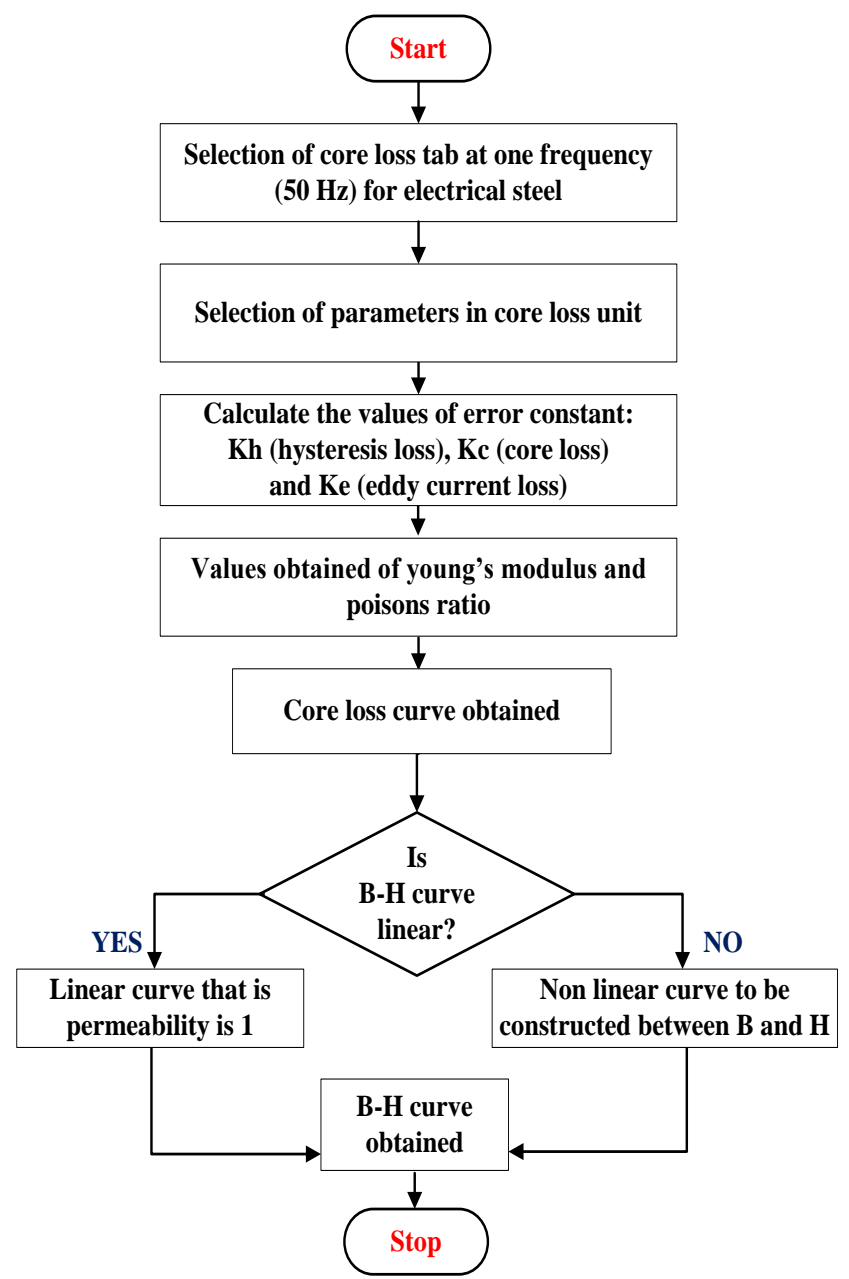

Fig. 5. Analysis of linear and nonlinear behavior of B-H curve.

In case of fault detection and reduction of unusual power transformers plays an important role in power system It is also important to detect the operating characteristics of transformer with repeat to desired time as well as the reliability of the equipment. It is well identified that power transformers certainly suffer the impacts of short-circuit electromagnetic forces in deal [27]. It states that AI based system is very convenient tools for power transformer early hidden faults accomplishes the opportunity and accurateness of prime analysis [28]-[31].

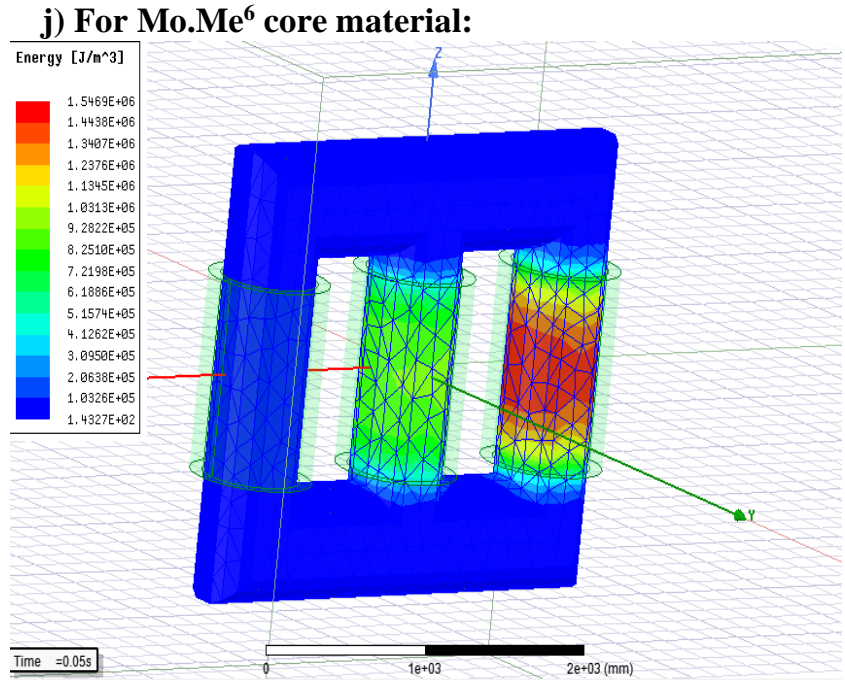

Fig. 6. Diagram of transformer core depicting the energy density.

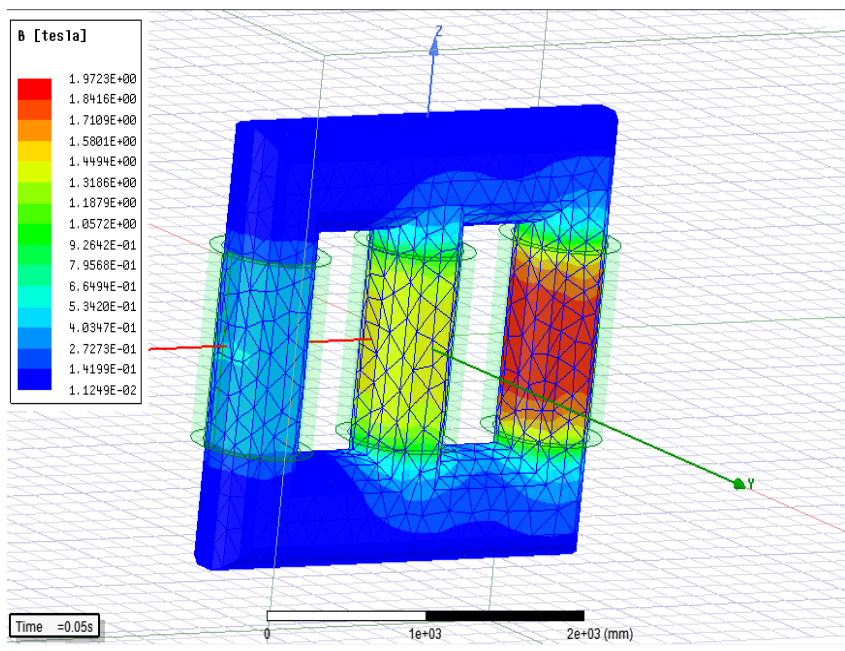

Fig. 7. Diagram of transformer depicting the magnetic flux density field on the core (referred from Table 2).

In equation (4), B is magnetic flux density in Tesla (T), $\mu$ is the permeability of core material and $\mathrm{H}$ is the magnetic flux intensity Ampere/meter $(\mathrm{A} / \mathrm{m}), \Phi$ is magnetic flux in Weber $(\mathrm{Wb})$ and $\mathrm{A}$ is area of surface of the core in $\operatorname{meter}^{2}\left(\mathrm{~m}^{2}\right)$. From the Fig.7 and Fig. 9 using the equation 4 the following conclusion is made that the material Mo.Me ${ }^{6}$ has more flux density than iron. Which states that if $\mathrm{B}$ will be greater then automatically permeability of core material will be greater, and the area of surface of core will be lesser, which means less space required by the core and small size of the transformer.

$$
B=\mu \cdot H=\frac{\emptyset}{A}
$$

Similarly, from the above the Fig. 6 and Fig. 8 the following conclusion can be made that, the energy density of the core material $\mathrm{Mo}^{\mathrm{Me}} \mathrm{C}^{6}$ is greater than iron signifying that the volume of the core material will be low. Hence, the core material required will be used in lesser quantity. Thus, cost and size of the transformer required will be low. 
k) For Iron core material:

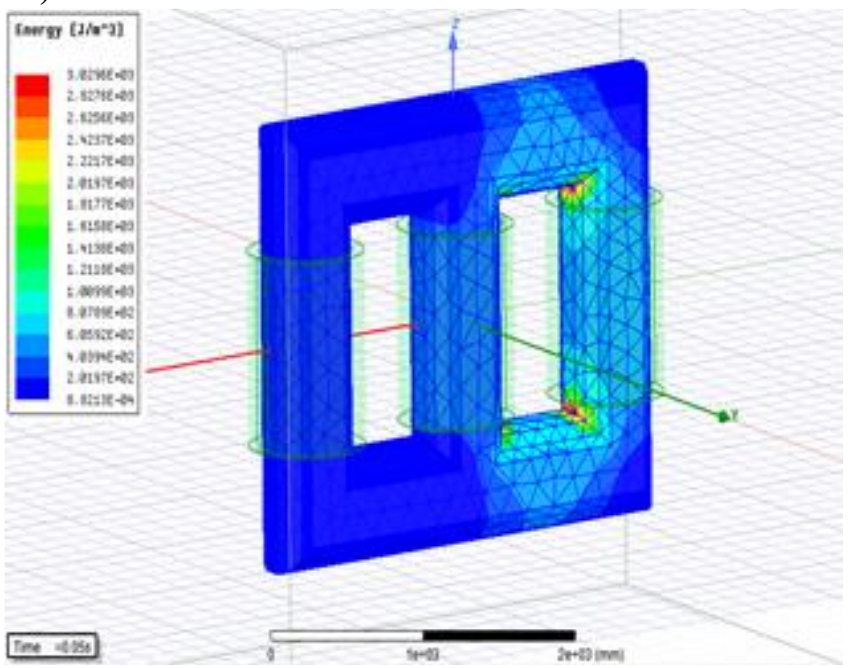

Fig. 8. Diagram of transformer core depicting the energy density.

\section{Simulation Result ANALYSis AND Discussions}

\section{A. Performance Evolution of Different Core Materials}

The results which are depicted in the tabular format with comparative analysis, based on the performance and the changing parameters, defines the working efficiency of the core transformer.

From the Table 3 and Table 4 some comparative analysis can be made which are as follows:

- If B-H Curve is linear then the losses are minimized otherwise a nonlinear B-H characteristics core material increases the losses.

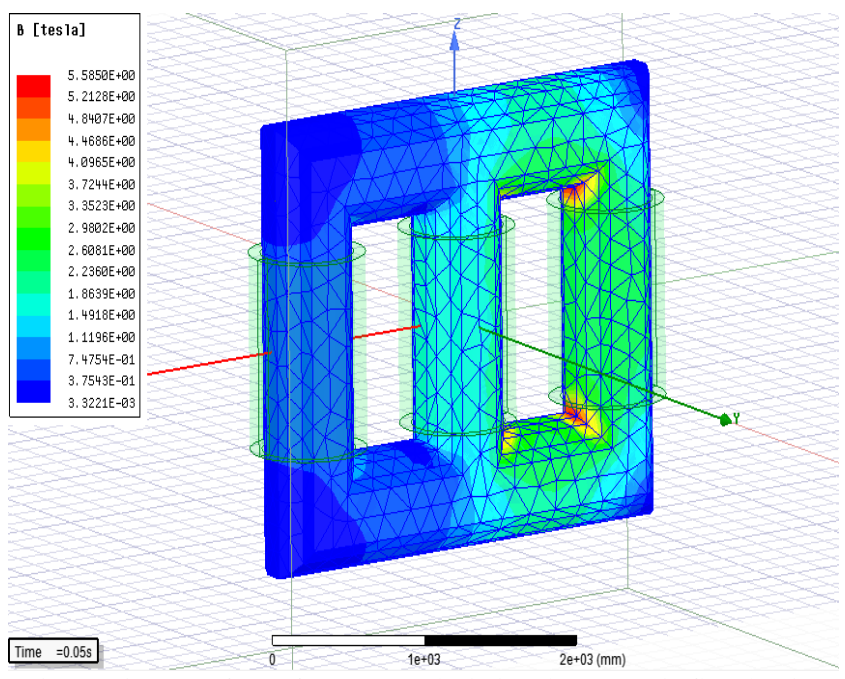

Fig. 9. Diagram of transformer core depicting the magnetic flux density field on the core (referred from Table 2).

TABLE 3: Mo.ME ${ }^{6}$ HAVE Less Losses In COMPARISON OF IRON MATERIAL For 3థ TRANSFORMER HAVING INPUT $20 \mathrm{KV}$

\begin{tabular}{|c|c|c|c|c|c|c|c|c|c|}
\hline \multirow[b]{2}{*}{ Sl. No. } & \multicolumn{4}{|c|}{ Core loss curve } & \multirow{2}{*}{$\begin{array}{l}\text { B-H } \\
\text { curve }\end{array}$} & \multirow{2}{*}{$\begin{array}{c}\text { Resistance } \\
\text { of winding } \\
\text { (m-ohm) }\end{array}$} & \multirow{2}{*}{$\begin{array}{c}\text { Average } \\
\text { core } \\
\text { loss }\end{array}$} & \multirow{2}{*}{$\begin{array}{l}\text { Average } \\
\text { hysteresis } \\
\text { loss }\end{array}$} & \multirow{2}{*}{$\begin{array}{c}\text { Average } \\
\text { eddy current } \\
\text { loss }\end{array}$} \\
\hline & $\begin{array}{c}\text { Coil } \\
\text { terminal }\end{array}$ & $\begin{array}{l}\text { Mass density } \\
\quad(w / k g)\end{array}$ & $\begin{array}{l}\text { Thickness } \\
\quad(\mathrm{mm})\end{array}$ & $\begin{array}{c}\text { Core } \\
\text { material }\end{array}$ & & & & & \\
\hline Instance 1 & 80 & 7860 & 0.27 & Iron & Yes & 2.0 & 37.2892 & 34.2260 & 3.0631 \\
\hline Instance 2 & 80 & 7000 & 0.27 & Mo.Me ${ }^{6}$ & Yes & 2.0 & 33.3005 & 30.2374 & 3.0631 \\
\hline Instance 3 & 70 & 7860 & 0.30 & Mo.Me ${ }^{6}$ & Yes & 1.0 & 44.3483 & 39.6346 & 4.7137 \\
\hline Instance 4 & 80 & 7860 & 0.30 & Iron & No & 2.0 & 46.3172 & 42.6597 & 3.6575 \\
\hline Instance 5 & 80 & 7860 & 0.30 & Mo.Me ${ }^{6}$ & No & 2.0 & 9.8333 & 9.0148 & 0.8185 \\
\hline Instance 6 & 80 & 7000 & 0.27 & Mo.Me ${ }^{6}$ & No & 2.0 & 8.7507 & 8.0877 & 0.6629 \\
\hline
\end{tabular}

TABLE 4: COMPARATIVE ANALYSIS OF DifFERENT LOSSES USING ONLY MO.ME ${ }^{6}$ MATERIAL FOR 3థ TRANSFORMER WiTH INPUT 200 KV

\begin{tabular}{|c|c|c|c|c|c|c|c|c|}
\hline \multirow[b]{2}{*}{ Sl. No. } & \multicolumn{3}{|c|}{ Core loss curve } & \multirow[b]{2}{*}{$\begin{array}{c}\text { B-H } \\
\text { curve }\end{array}$} & \multirow{2}{*}{$\begin{array}{c}\text { Resistance } \\
\text { of winding } \\
\quad(\mathrm{ohm})\end{array}$} & \multirow{2}{*}{$\begin{array}{c}\text { Average } \\
\text { core } \\
\text { loss }\end{array}$} & \multirow{2}{*}{$\begin{array}{c}\text { Average of } \\
\text { hysteresis } \\
\text { loss }\end{array}$} & \multirow{2}{*}{$\begin{array}{c}\text { Average } \\
\text { eddy current } \\
\text { loss }\end{array}$} \\
\hline & $\underset{\text { terminal }}{\text { Coil }}$ & $\begin{array}{c}\text { Mass Density } \\
(w / k g)\end{array}$ & $\begin{array}{l}\text { Thickness } \\
\quad(\mathrm{mm})\end{array}$ & & & & & \\
\hline Instance 7 & 80 & 7650 & 0.27 & Yes & 2.5 & 194.9642 & 172.6563 & 22.3079 \\
\hline Instance 8 & 80 & 8000 & 0.30 & Yes & 2.5 & 205.8764 & 178.3460 & 27.5304 \\
\hline Instance 9 & 80 & 7650 & 0.30 & Yes & 1.0 & 506.9564 & 464.8197 & 42.1367 \\
\hline Instance 10 & 80 & 8000 & 0.30 & No & 2.0 & 95.5048 & 87.6191 & 78.857 \\
\hline Instance 11 & 80 & 8000 & 0.30 & No & 2.5 & 63.3933 & 58.1015 & 5.2918 \\
\hline
\end{tabular}

Following Fig. 10 and Fig. 11 are the input voltage characteristics of core type transformer at different ratings, which showing the variation in input voltages based on proposed Mo.Me $\mathrm{Me}^{6}$ material. 


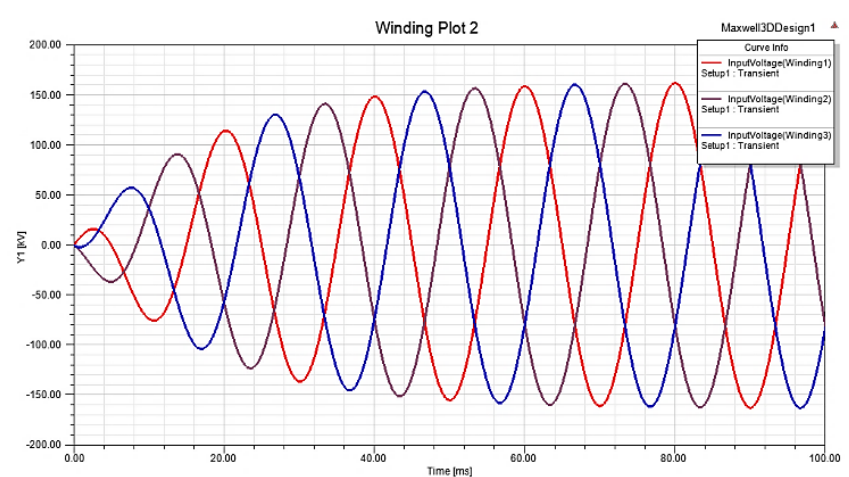

Fig. 10. Input voltage graph for core type transformer (20 KV rating).

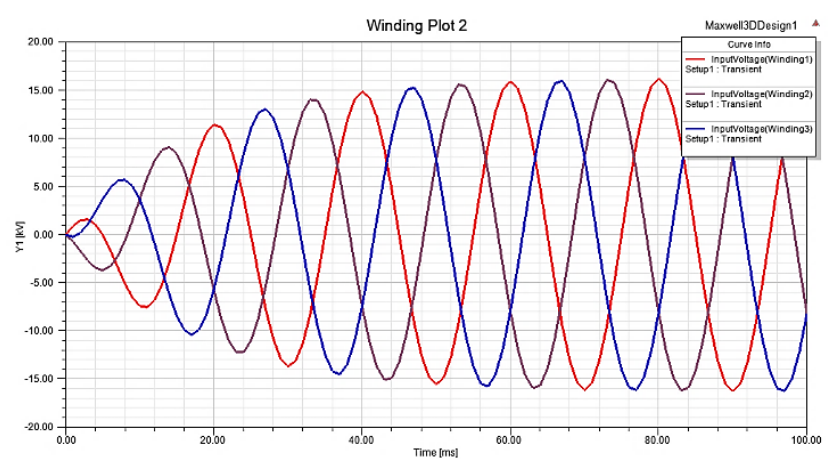

Fig. 11. Input voltage graph for core type transformer (200 KV rating)

\section{B. Testing of Designed Mo.Me $e^{6}$ Core Material}

The input voltage graphs of Fig. 12 and Fig. 13 are showing the all three phase voltages with different phases in the transient system given as input to both the three-phase core type transformer. Similarly, 3D rectangular plots of input voltages are shown where: $\mathrm{x}$-axis: time $(\mathrm{ms}), \mathrm{y}$-axis: time $(\mathrm{ms})$ and z-axis: voltage (v).
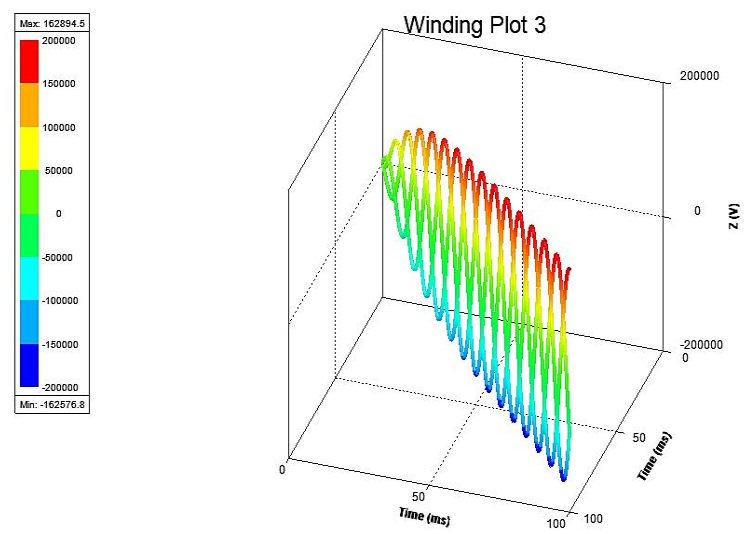

Fig. 12. Rectangular 3D plot of input voltages in $200 \mathrm{KV}$ transformer
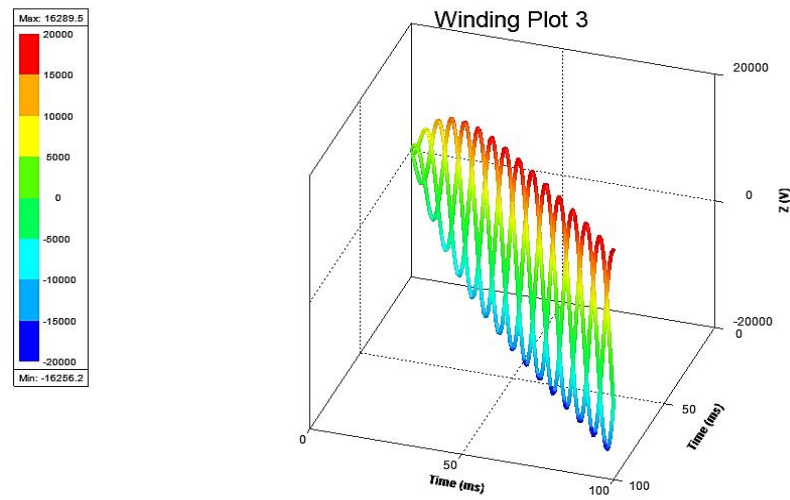

Fig. 13. Rectangular 3D plot of input voltages in $20 \mathrm{KV}$ transformer. a) For $3 \Phi$ transformer with $20 \mathrm{KV}$ input rating: $\mathrm{x}$-axis: time (ms) and y-axis: current (ampere), the graphs of current at different instance of the core transformer:
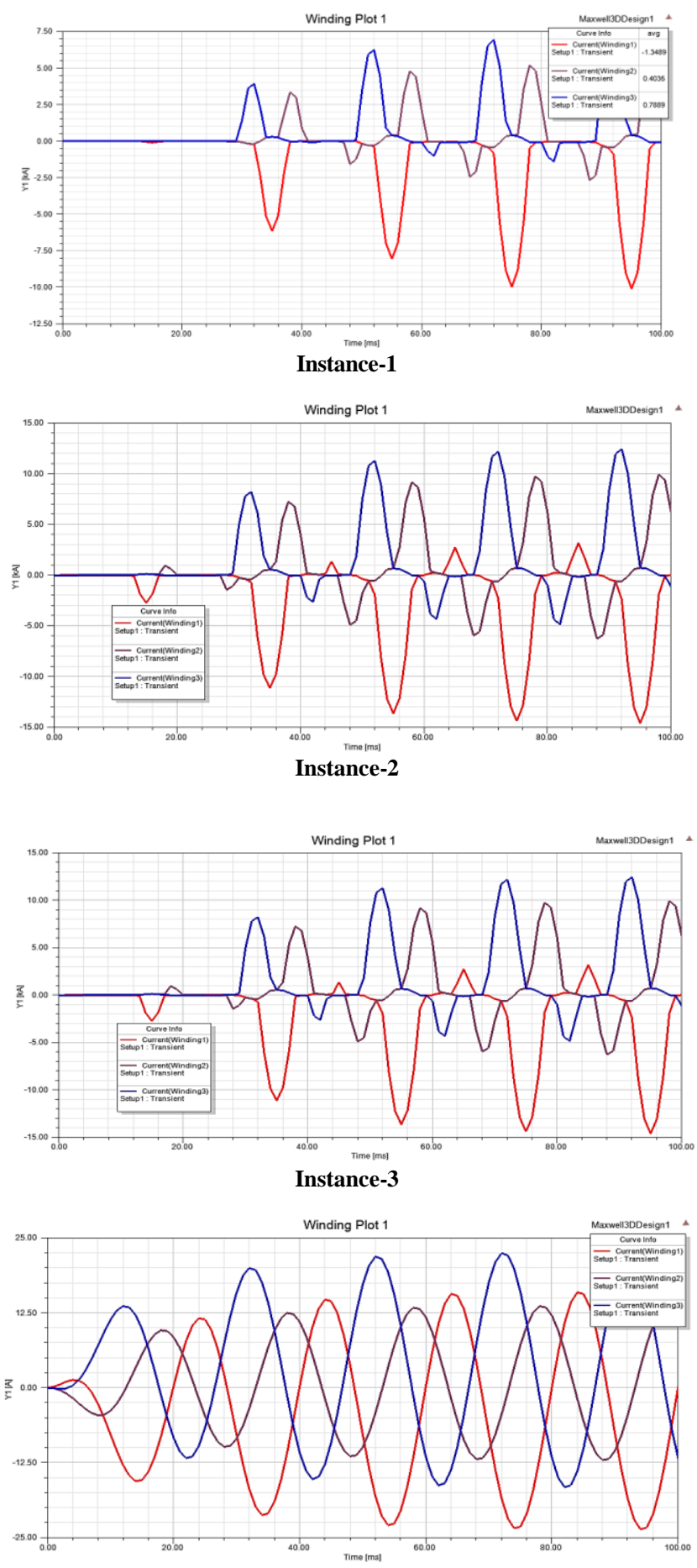

Instance-4

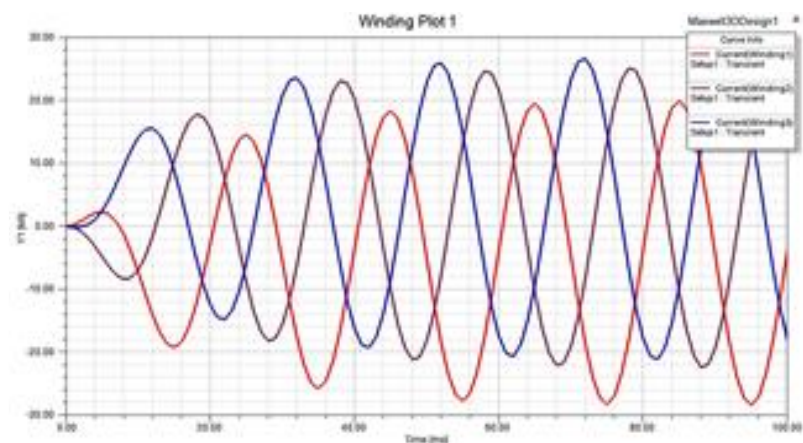

Instance-5 


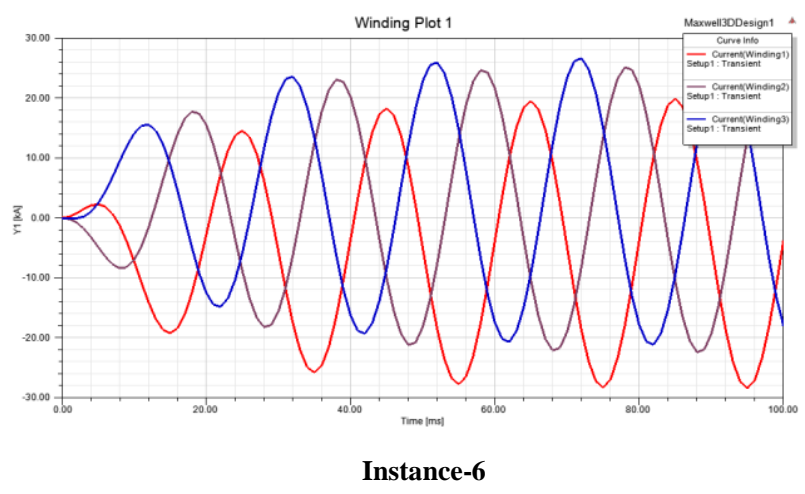

Fig. 14. Current waveform of different instances (1 to 6) at $20 \mathrm{KV}$ ratings core transformer.

From all the above figures of the instance 1-6 represented in the tables following observations are referred from Table 3.

In the instance 1,2 and 3 it is observable that the current graphs are not linear as they are having nonlinear B-H curve which have their effect on the current. As because the core material has an effect generating harmonics and distortions in the current which is in the transformer. In the instance 4,5 and 6 it is observable that the current graphs are linear due to linear B-H curve. These curves are linear, and harmonics are not present.

b) $3 \Phi$ transformer with $200 \mathrm{KV}$ input rating: $\mathrm{x}$-axis: time (ms) and y-axis: current (in ampere).
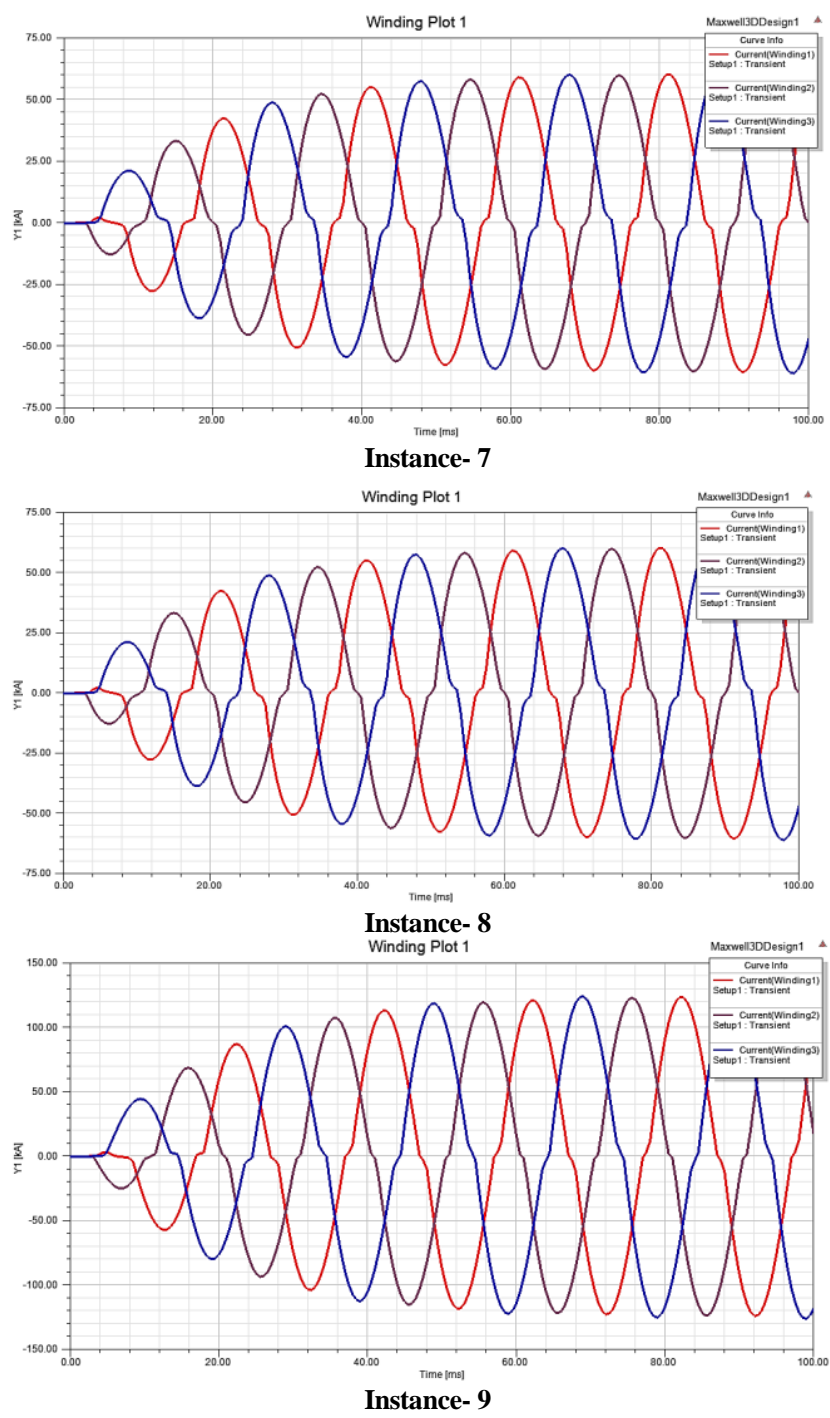
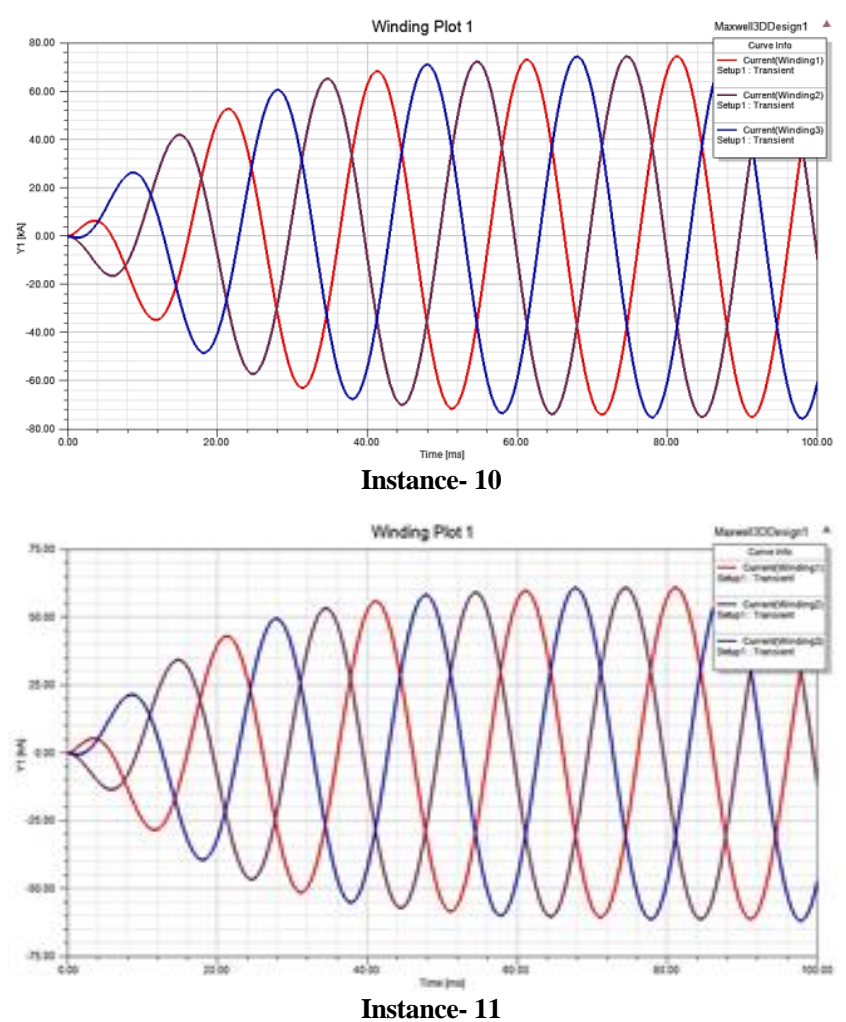

Fig. 15. Current waveform of different instances (7 to 11) at $200 \mathrm{KV}$ ratings core transformer

The cause of distorted curves is due to some parameters, which have been already explained in the flowchart diagram of Fig. 5, From above all the figure 15 of the instance 7-11 represented in the tables following observations are made which are referred from Table 4.

In the instance 7,8 and 9 it is observable that the current graphs are not linear as there is presence of some delay is present in the curves. The reason is that the B-H curve, which have their effect on the current. As because the core material has an effect generating harmonics in the current which is in the transformer. Harmonics are referred as voltages and currents appearing on power system at frequencies, which comprises of multiplications integers of generated frequency [32]-[34].

In the instance 10 and 11 it is observable that the current graphs are linear due to linear B-H curve. These curves are linear, and harmonics are not present. They can be observed having ideal current graph.

From above all the results it is well observable that how a transformer model behaves when its certain parameters are changed accordingly.

\section{COMPARATIVE ANALYSIS OF TRANSFORMER EFFICIENCY BASED ON DIFFERENT CORE MATERIALS}

As the efficiency of transformer is defined by formulas:

$$
\text { Total losses }=\text { Copper loss }+ \text { Core loss }
$$

Efficiency $\left(\mathrm{n}_{\mathrm{\eta}}\right)=\frac{\text { output }}{\text { output }+ \text { Total losses }} \times 100 \%$ 


\section{A. For Iron core material}

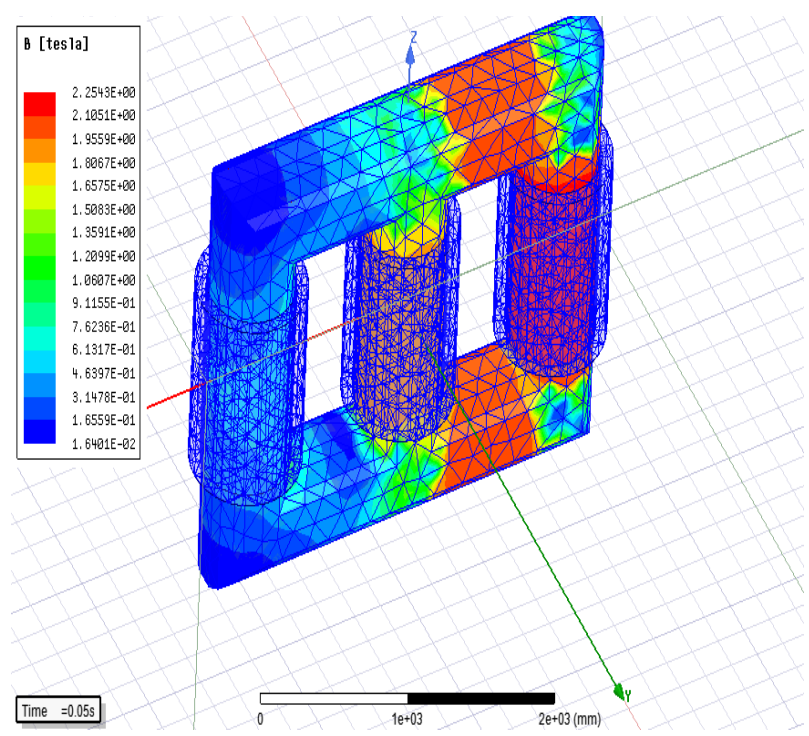

Fig. 16. Iron magnetic flux density at Instance-1.

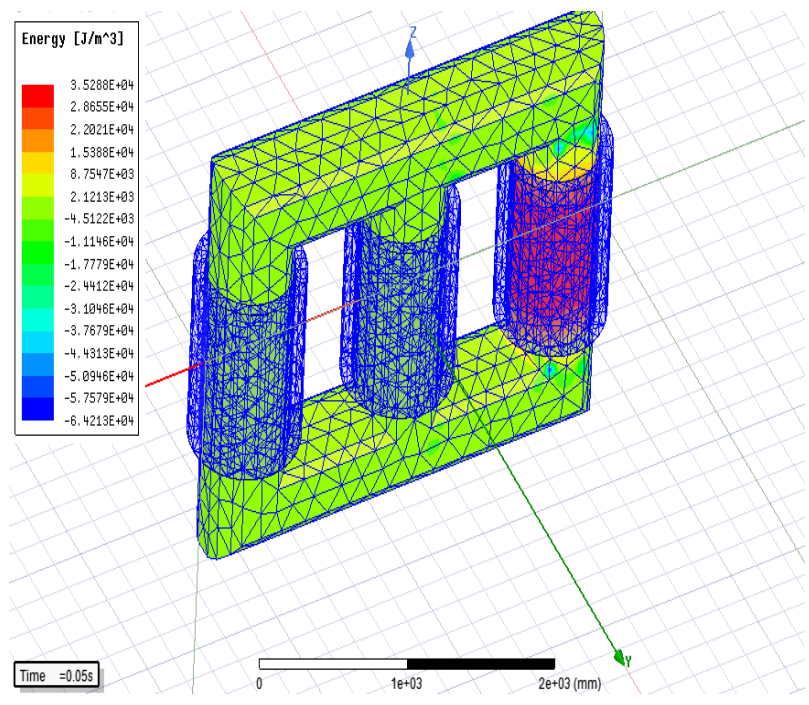

Fig. 17. Iron energy density at Instance-1 (referred from table 3)

Magnitude of total phase current total phase current:

$=1.3489+0.4035+0.7889=2.5413 K A$

(For three phase $\left.=\frac{2.5413}{3}=0.8471 \mathrm{KA}\right)$

Copper loss $=I^{2} R$

Here, Line current $\left(\mathrm{I}_{\mathrm{L}}\right)=$ Phase current $\times \sqrt{3}$

$$
\mathrm{I}_{\mathrm{L}}=0.8471 \times \sqrt{3}=1.4672 \mathrm{KA}
$$

Copper loss $=\frac{1.4672^{2} \times 10^{6} \times 2}{10^{3}}=4.3053 \mathrm{KW}$

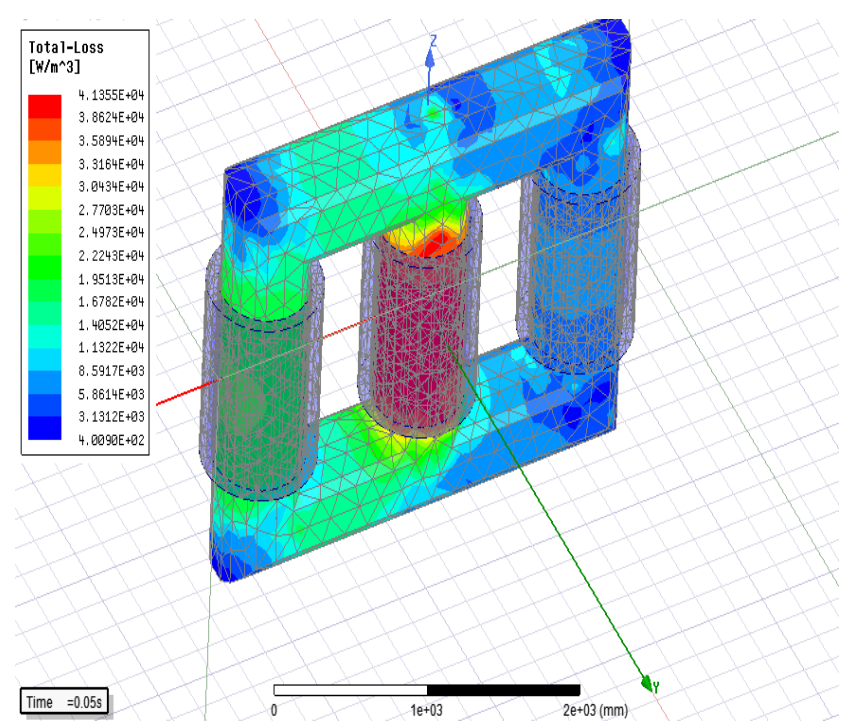

Fig. 18. Iron total losses.

Total Losses $=37.2892+4.3053=41.594 K W(7)$

Magnitude of total three phase voltage:

$$
\mathrm{V}_{\mathrm{Ph}}=\frac{0.2066+0.5126+0.3353}{3}=0.3514 K V
$$

Output power $=V \times I_{L}=0.3514 \times 1.4672 \times 10^{3}$

$$
=515.57 \mathrm{KW}
$$

From equation (7) and (8);

$$
\begin{gathered}
\text { Efficiency }=\frac{515.57}{(515.57+41.594)} \times 100 \\
\eta_{\text {transformer }}=92.53 \% \text { (with iron core matrial) }
\end{gathered}
$$

\section{B. For Mo.Me ${ }^{6}$ Core Material}

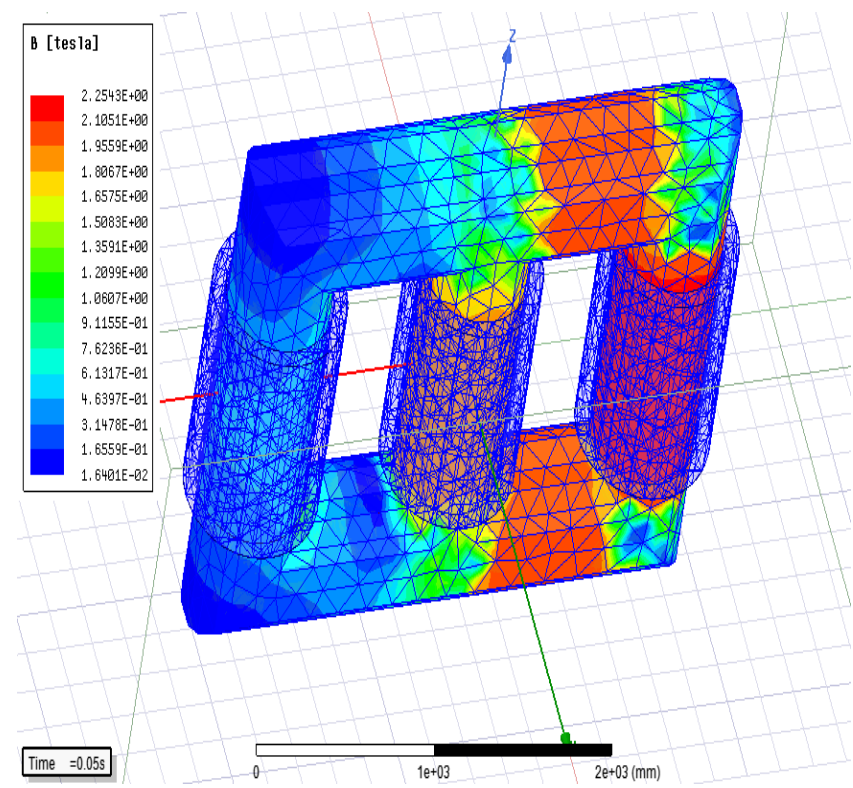

Fig. 19. Material $\left(\mathrm{Mo}_{\mathrm{Me}} \mathrm{M}^{6}\right)$ magnetic flux density at Instance-2. 


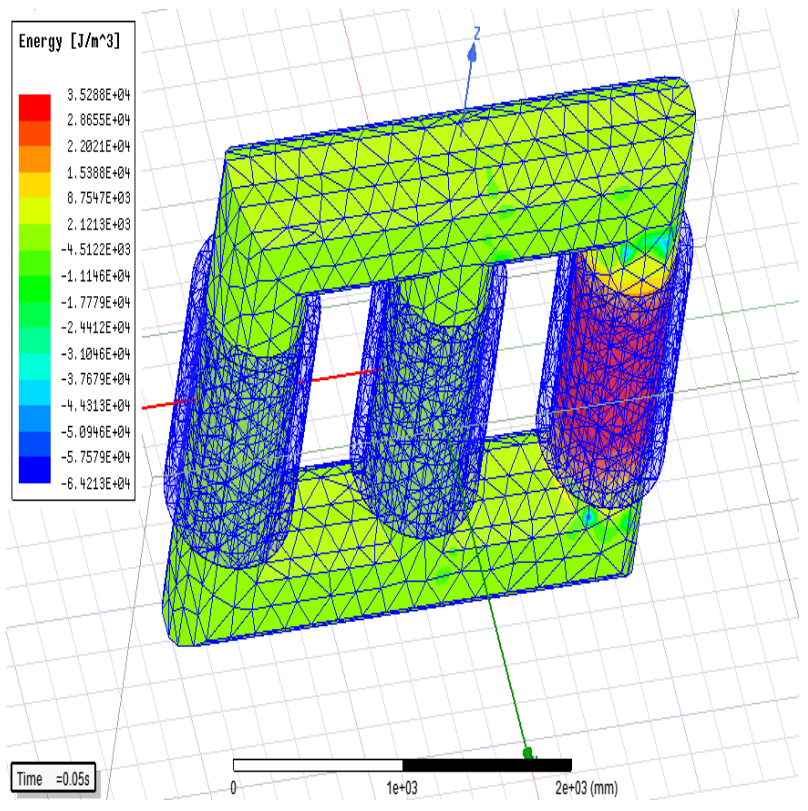

Fig. 20. Material $\left(\mathrm{Mo.Me}^{6}\right)$ energy density at Instance-2.

Magnitude of total phase current:

$=1.3489+0.4035+0.7889=2.5413 k A$

(For three phase $\left.=\frac{2.5413}{3}=0.8471 \mathrm{KA}\right)$

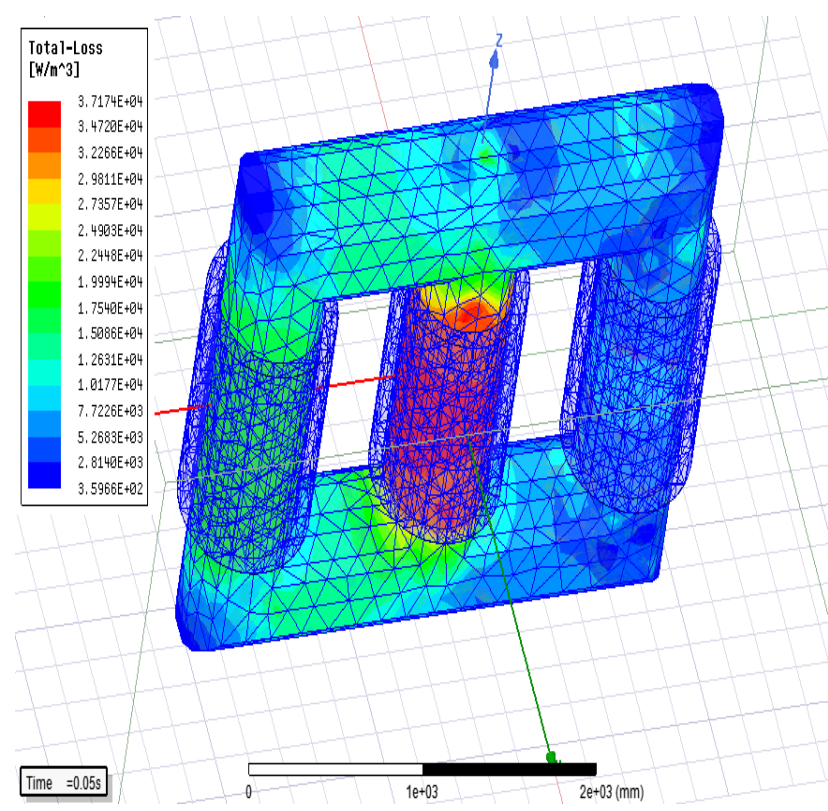

Fig. 21. Material $\left(\mathrm{Mo}_{\mathrm{Me}}{ }^{6}\right.$ ) total losses (referred from Table 4).

Copper loss $=I^{2} R$

Here, Line current $\left(\mathrm{I}_{\mathrm{L}}\right)=$ Phase current $\times \sqrt{3}$

$$
\begin{gathered}
\mathrm{I}_{\mathrm{L}}=0.8471 \times \sqrt{3}=1.4672 \mathrm{KA} \\
\text { Copper loss }=\frac{1.4672^{2} \times 10^{6} \times 2}{10^{3}}=4.3053 \mathrm{KW}
\end{gathered}
$$

Total losses $=33.3005+4.3053 \mathrm{kw}=37.6058 \mathrm{KW}(9)$

Magnitude of total three phase voltage:

$$
\mathrm{V}_{\mathrm{Ph}}=\frac{0.2066+0.5126+0.3352}{3}=0.3514 \mathrm{KV}
$$

Output power $=V \times I_{L}=0.3514 \times 1.4672 \times 10^{3}$

$$
=515.57 \mathrm{KW}
$$

From equation (9) and (10);

$$
\begin{gathered}
\text { Efficiency }=\frac{515.57}{(515.57+37.6058)} \times 100 \\
\eta_{\text {transformer }}=93.20 \%\left(\text { with Mo.Me }{ }^{6} \text { material }\right)
\end{gathered}
$$

Therefore, $\mathrm{MoMe}^{6}$ has better efficiency than iron core material. If the losses decrease, then automatically efficiency of transformer increases. The increase is observed when in the designed new material Mo.Me $\mathrm{e}^{6}$ some defined parameters are changed accordingly. As for the new material Mo.Me ${ }^{6}$, doping criteria is one of the better idea to observe the effects on working of transformer. As because the core material

\begin{tabular}{|c|c|c|c|c|}
\hline Mat & rial: $\mathrm{Mo}_{0} \mathrm{Me}^{6}$ & & |Cartesian & \\
\hline & berties of the Material- & & & \\
\hline & Name & Type & Value & Units \\
\hline & Relative Permeability & Nonlinear & B-H Curve. & \\
\hline & Bulk Conductivity & Simple & 0 & siemens/m \\
\hline & Magnetic Coercivity & Vector & & \\
\hline & - Magnitude & Vector Mag & 0 & A_per_meter \\
\hline & - XComponent & Unit Vector & $\sqrt[1]{\text { Ontimal }}$ & \\
\hline & - $Y$ Component & Unit Vector & \begin{tabular}{l|l}
0 & $\begin{array}{l}\text { Optimal value } \\
\text { with iron and }\end{array}$
\end{tabular} & $\begin{array}{l}\text { es compared } \\
\text { ferrite core }\end{array}$ \\
\hline & - Z Component & Unit Vector & $0 L$ & \\
\hline & Core Loss Model & & Electrical Steel & $w / m^{\wedge} 3$ \\
\hline & $\cdot \mathrm{Kh}$ & Simple & & \\
\hline & $\cdot K_{c}$ & Simple & 0.14804406601634 & \\
\hline & $\cdot \mathrm{Ke}$ & Simple & 0 & \\
\hline & - Kdc & Simple & 0 & \\
\hline & - Equiv. Cut Depth & Simple & 0 & $\mathrm{fm}$ \\
\hline & Mass Density & Simple & 8000 & $\mathrm{~kg} / \mathrm{m}^{\wedge} 3$ \\
\hline & Composition & & Solid & \\
\hline & Young's Modulus & Simple & 0 & $\mathrm{~N} / \mathrm{m}^{\wedge} 2$ \\
\hline & Poisson's Ratio & Simple & 0 & \\
\hline & Magnetostriction & Custom & Edit.. & \\
\hline & Inverse Magnetostriction & Custom & Edit.. & \\
\hline
\end{tabular}
plays important role in the transformer efficiency and losses. Just like other materials, Mo.Me ${ }^{6}$ has good conductivity which is $1000,000 \mathrm{Siemens} / \mathrm{m}$. The Fig. 15, shows the parameters of $\mathrm{Mo}^{\mathrm{Me}} \mathrm{e}^{6}$ which makes it a good conducting material.

Fig. 22 Properties of proposed designed core material $\left(\mathrm{Mo.Me}^{6}\right)$ in ANFIS parameter software tool at instance 8 .

$\mathrm{MoMe}^{6}$ has batter efficiency than iron core material. If the losses decrease, then automatically efficiency of transformer increases. That increase is observable when in the designed new material Mo. $\mathrm{Me}^{6}$ some defined parameters are changed accordingly. As for the new material Mo. $\mathrm{Me}^{6}$, doping criteria is one of the better idea to observe the effects on working of transformer. As because of the core material plays important role in the transformer efficiency and losses. Just like other materials, Mo.Me ${ }^{6}$ has good conductivity which is 1000,000 Siemens $/ \mathrm{m}$. The Fig. 22, shows the parameters of Mo.Me which makes it a good conducting material.

From Fig. 23, it is observable that the material designed has composition of electrical steel. The material can be doped with other material with different compositions as it has good 
conductivity and falls in the category of conductors as mentioned in table.5.

TABLE 5: COMPARATIVE ANALYSIS OF DIFFERENT MATERIALS BASED ON PROPERTIES

\begin{tabular}{|c|c|c|c|c|c|}
\hline $\begin{array}{c}\text { Core } \\
\text { Material }\end{array}$ & $\begin{array}{c}\text { Relative } \\
\text { Permeability }\end{array}$ & $\begin{array}{c}\text { Young's } \\
\text { Modulus } \\
\left(\mathrm{N} / \mathrm{m}^{2}\right)\end{array}$ & $\begin{array}{l}\text { Poisson's } \\
\text { Ratio }\end{array}$ & $\begin{array}{l}\text { Bulk Conductivity } \\
\text { (Siemens } / \mathrm{m})\end{array}$ & $\begin{array}{l}\text { Mass Density } \\
\quad(w / k g)\end{array}$ \\
\hline Iron & 4000 & $19.5 \times 10^{10}$ & 0.28 & $1.03 \times 10^{07}$ & 7800 \\
\hline Ferrite & 1000 & $1.29 \times 10^{11}$ & 0.08 & 0.01 & 4600 \\
\hline $\mathrm{MoMe}^{6}$ & 2000 & $0.7 \times 10^{11}$ & 0.02 & 0.7 & 8000 \\
\hline
\end{tabular}

The nature of material can be changed accordingly through variations of parameters for different applications. Table.5 shows the improved and better core design of Mo.Me $\mathrm{Me}^{6}$, material which have good efficiency and less losses.
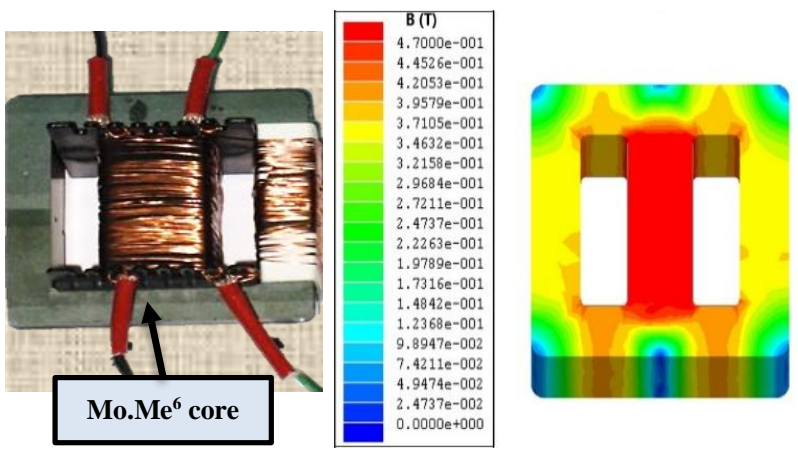

(a) (b)

Fig.23 (a) Hardware prototype of core type transformer with Mo.Me ${ }^{6}$ material (b) flux density range $|\mathrm{B}|$ values of Mo.Me6 core surface in 3D ANSYS electronic desktop platform.

Due to the transient and sudden change in current, Hysteresis curve is used to examine the total core losses, which are not dependent of change in temperature as well as frequencies. fig. 23 (b) implements for gap thickness $0 \mu \mathrm{m}$ and 10A saturation current. Further which will showing that Mo. $\mathrm{Me}^{6}$ have improved hysteresis curve than other conventionally core materials. Thus, in this research we carried out the hardware validation of transformer core which ranges from lower to higher rating. In figure 23 (a) number of winding are 2 with 45 turns used. The material Mo.Me ${ }^{6}$ having primary permeability $\left(\mu_{\mathrm{i}}\right)$ is $2000 \pm 10 \%$ at $27{ }^{\circ} \mathrm{C}$ temperature, magnetic field strength $(\mathrm{H})$ is $1200 \mathrm{~A} / \mathrm{m}$, mass conductivity 8000 , saturation flux density $\left(\mathrm{B}_{\text {sat }}\right)$ is around $440 \mathrm{mT}$ at $27^{\circ} \mathrm{C}$ and curie temp $\left(\mathrm{T}_{\mathrm{c}}\right)$ is more than $210{ }^{\circ} \mathrm{C}$.

\section{CONCLUSIONS}

In our proposed methodology, the optimal design of core type power transformer and their performance analysis have been done. The calculation of losses parameters was employed that able to analyse the working of transformer in varying conditions whether they are associated with core parameters, ratings etc. There is an advantage of using the ANSYS software that it allows the user to change the working environment medium according to the need of the consumer. Also, toroidal transformers can be utilized for low frequency power applications as in the applications related to power electronics. The toroidal transformers are at commonly used where components volume or weight is at priority. AI based monitoring of transformer components is also a better method of application. AI based on-line monitoring is a tool that can assess the state of these valued assets in real time. Doping of core material opens up an opportunity for more distinct and varied results. But their working age and error generation cannot be predicted in this software. It can be use as the future work and opportunity to discuss these parameters by using AI techniques. As it will be more advent in the performance analysis using artificial neural networks approach that can be used to train the required left parameters. In this study, by reducing no-load losses, then overall efficiency can be increased which will enhance the life of power transformer. Manufacturer of the power transformer can experimentally implement the $\mathrm{Mo}_{\mathrm{Me}} \mathrm{C}^{6}$ core material than other core materials for a lesser amount of losses with the help of finite element method.

\section{REFERENCES}

[1] H. D. Mehta, R.M.P.: "A Review on Transformer Design Optimization and Performance Analysis Using Artificial Intelligence Techniques," Int. J. Sci. Res., 2014.

[2] Patel, A., Bapodariya, N., Panchal, H., Smart, N., Bhatt, K.: "3-Phase Core Type of Transformer and Modification of Symmetrical Star Shaped Core," International Journal of Advance Engineering and Research Design 324-331, 2017.

[3] AC and DC machine, Vol-II, B. L THAREJA, Accessed on October,7 https://www.amieindia.in/downloads/ebooks/electrical2-theraja.pdf (Access on August 2020)

[4] Dhonge, D.D., Swami, P.S., Thosar, A.G.: "Developing Artificial Neural Network ANN Model for Fault Diagnosis of Power Transformer," International Journal of Scientific and Engineering Research, 1127-1132, 2015.

[5] Tripathy, M., Maheshwari, R.P., Verma, H.K.: "Power transformer differential protection based on optimal probabilistic neural network, " IEEE Trans. Power Deliv. 25, 102-112, 2010.

[6] Hsieh, M.F., Hsu, C.H., Fu, C.M., Huang, Y.M.: "Design of Transformer With High-Permeability Ferromagnetic Core and Strengthened Windings for Short-Circuit Condition," IEEE Trans. Magn. 51, 2-5, 2015.

[7] Suttisinthong, N., Pothisarn, C.: Analysis of Electrical Losses in Transformers using Artificial Neural Networks. II, 12-15, 2014

[8] Anoop, S., Naufal, N.: Monitoring of winding temperature in power transformers - A study. 2017 Int. Conf. Intell. Comput. Instrum. Control Technol. ICICICT, 1334-1337, 2018.

[9] Kittan, S., Kornhuber, S., Kastel, P., Nitsche, G., Valtin, G., Weise, M.: "Review and Implementation of Transformer Health Index Methods in line with the Development of a Condition Assessment Tool, " Int. Conf. Diagnostics Electr. Eng. Diagnostika 2018.

[10] Ismagilov, F.R., Vavilov, V.E., Gusakov, D. V.: "High-Efficiency Transformer-Rectifier Unit: Design and Experimental Studies," 2019 26th Int. Work. Electr. Drives Improv. Effic. Electr. Drives- IWED Proc. 1-4, 2019.

[11] J. Survilo, "Transformer design according to criteria and load profile", ((IEEE 58th RTUCON), Riga, 2017.

[12] Stergiou, C.A., Zaspalis, V.: "Cobalt-Induced Performance Instabilities of Mn-Zn Ferrite Cores,” IEEE Trans. Magn. 54, 1-8, 2018.

[13] Litovets, A. V., Serikov, A. V., Serikov, V.A.: "Energy efficiency increasing for the power transformer by means of the liquid heating unit.” Int. Conf. Ind. Eng. Appl. Manuf. ICIEAM 2017 - Proc. 1-4, 2017.

[14] Suppitaksakul, C., Saelee, V.: "Application of Artificial Neural Networks for electrical losses estimation in three-phase transformer," 6th Int. Conf. Electr. Eng. Comput. Telecommun. Inf. Technol. ECTICON 2009. 1, 248-251, 2009.

[15] Nnachi, G.U., Akumu, A.O., Richards, C.G., Nicolae, D. V.: "Estimation of no-Load Losses in Distribution Transformer Design Finite Element Analysis Techniques in Transformer Design," IEEE PES/IAS Power Africa, Power Africa 2018. 527, 527-531, 2018.

[16] ANSYS_electronic_software_2020TM_version:https://www.ansys.co $\mathrm{m} / \mathrm{en}$-in/products/electronics (2020).

[17] Isa, M.M., Kadir, M.Z.A.A., Gomes, C., Azis, N., Izadi, M., Alyozbaky, O.S.H.: "Analysis on magnetic flux density and core loss 
for hexagonal and butt-lap core joint transformers"' IEEE 2nd Annu. South. Power Electron. Conf. SPEC 2016.

[18] W. Sun, L. Yang, J. Hao and F. Zare, "3D Electric Field Simulation of Converter Transformer with Real Insulation Materials Utilized in HVDC Systems," IEEE International Conference on High Voltage Engineering and Application (ICHVE), ATHENS, Greece, pp. 1-4, 2018.

[19] Wang, Z., Wu, W.: "Effect of higher insulation material thermal conductivity on transformer temperature rise," $34^{\text {th }}$ Electr. Insul. Conf EIC 2016. 358-361, 2016.

[20] Digalovski, M., Najdenkoski, K., Rafajlovski, G.: "Impact of current high order harmonic to core losses of three-phase distribution transformer, " IEEE EuroCon 2013. 1531-1535, 2013.

[21] De León, F., Purushothaman, S., Qaseer, L.: "Leakage inductance design of toroidal transformers by sector winding," IEEE Trans. Power Electron. 29, 473-480, 2014.

[22] Saad, M., Tenyenhuis, E.: "On-line gas monitoring for increased transformer protection, ” IEEE Electr. Power Energy Conf. EPEC Oct $1-4,2018$.

[23] Semiconductor materials standard available online on: https://memechanicalengineering.com/comparison-between-conductorssemiconductors-and-insulators (2019).

[24] Silva, D.C.L., Sousa, R.H., Lima, F.K.A., Branco, C.G.C.: "Study of energy efficiency in dry-type transformer under sub- and inter harmonic in the power supply voltage," In: 2015 IEEE 13th Brazilian Power Electronics Conference and 1st Southern Power Electronics Conference (COBEP/SPEC). pp. 1-6. IEEE (2015).

[25] Rahimpour, H., Mitchell, S., Tusek, J.: "The application of sweep frequency response analysis for the online monitoring of power transformers, " Proc. 2016 Australas. Univ. Power Eng. Conf. AUPEC 2016.

[26] Fu Yang, Zhang liang: "Comprehensive method detecting the status of the transformer based on the artificial intelligence," 200090, 16381643, 2005.

[27] Zhang, H., Wang, S., Yuan, D., Tao, X.: "Double-Ladder Circuit Model of Transformer Winding for Frequency Response Analysis Considering Frequency-Dependent Losses, "' IEEE Trans. Magn. 51, 14, 2015.

[28] Yang, Q.P., Li, M.Q., Mu, X.Y., Wang, J.: “Application of artificial intelligence (AI) in power transformer fault diagnosis". 2009 Int. Conf. Artif. Intell. Comput. Intell. AICI 2009. 4, 442-445, 2009.

[29] H. A. Illias, K. C. Chan and H. Mokhlis, "Hybrid feature selectionartificial intelligence-gravitational search algorithm technique for automated transformer fault determination based on dissolved gas analysis, " in IET Generation, Transmission \& Distribution, vol. 14, no. 8, pp. 1575-1582, 24 4, 2020

[30] M. Amir and S. K. Srivastava, "Analysis of MPPT Based Grid Connected Hybrid Renewable Energy System with Battery Backup," 2018 International Conference on Computing, Power and Communication Technologies (GUCON), Greater Noida, Uttar Pradesh, India, 2018, pp. 903-907, doi: 10.1109/GUCON.2018.8674902.

[31] M. Amir and Zaheeruddin, "ANN Based Approach for the Estimation and Enhancement of Power Transfer Capability," 2019 International Conference on Power Electronics, Control and Automation (ICPECA), New Delhi, India, 2019, pp. 1-6, doi: 10.1109/ICPECA47973.2019.8975665.

[32] X. Zhao et al., "Experimental Evaluation of Transformer Internal Fault Detection Based on V-I Characteristics," in IEEE Transactions on Industrial Electronics, vol. 67, no. 5, pp. 4108-4119, May 2020.

[33] L. Zhou, J. Jiang, X. Zhou, Z. Wu, T. Lin and D. Wang, "Detection of transformer winding faults using FRA and image features," in IET Electric Power Applications, vol. 14, no. 6, pp. 972-980, 2020.

[34] Amir M., Srivastava S.K. (2019) Analysis of Harmonic Distortion in PV-Wind-Battery Based Hybrid Renewable Energy System for Microgrid Development. In: Mishra S., Sood Y., Tomar A. (eds) Applications of Computing, Automation and Wireless Systems in Electrical Engineering. Lecture Notes in Electrical Engineering, vol 553. Springer, Singapore. https://doi.org/10.1007/978-981-13-67724_107.

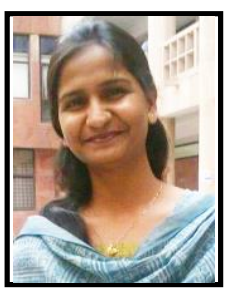

Dr. Shabana Urooj received the B.E. degree in electrical engineering and the M.Tech. degree in electrical with a specialization in instrumentation and control from Aligarh Muslim University, Aligarh, India, in 1998 and 2003, respectively, and the $\mathrm{Ph} . \mathrm{D}$. degree in biomedical instrumentation from the Department of Electrical Engineering, Jamia Millia Islamia (A Central University), New Delhi, India, in 2011.,She has approximately three years of industrial and more than 14 years of experience in academics. Since 2011, she has been a Faculty Member with the Department of Electrical Engineering, Gautam Buddha University, Greater Noida, India. She has authored or coauthored over 75 papers, which are published in international journals and conference proceedings. Her current research interests include material research, biomedical and environmental instrumentation, sensors system, and computer-based techniques for diagnosis of chronic diseases., Dr. Urooj has been a member of the Executive Committee of the IEEE Delhi Section, India, since 2010. She is an Associate Member of the American Ceramic Society and a member of the Electronic Division from 2012 to 2013. She is a member of the Computer Society of India and a Life Member of the Indian Society of Technical Education.

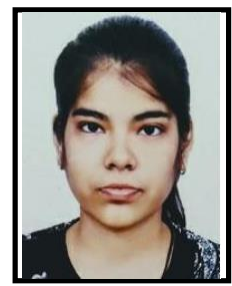

Ms. Tanya Singh was born in UP, India on October 1, 1996. She received her B.Tech degree in electrical engineering and M.Tech degree in the specialization of Power Electronics and Drives in year 2019 from Gautam Buddha University, Greater Noida, Uttar Pradesh, India. Her research interests include Power system dynamics, Power transformers, Optimization techniques.

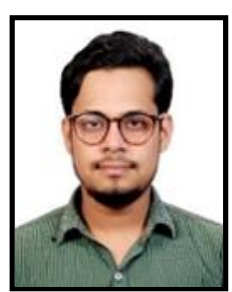

Mr. Mohammad Amir received the B.Tech. degrees in electrical engineering from Integral University, Lucknow, India, in 2015, and the M.Tech. degree in specialization of power electronics and drives from the Madan Mohan Malaviya University of Technology (MMMUT A Govt. University), Gorakhpur, India, in 2018, A meritorious student throughout. Mr. Amir was a recipient of MHRD fellowship, Graduate Aptitude Test in Engineering (GATE) fellow also the researcher of several government and ministry funded projects. He is actively IEEE young professional of Asia pacific, also the reviewer of many prestigious international journals. He has published many research papers in Journals and International conferences. His current research interest includes; electric vehicles, intelligent optimization techniques, microgrid developments, renewable energy applications, energy management, smart microgrid and power market.

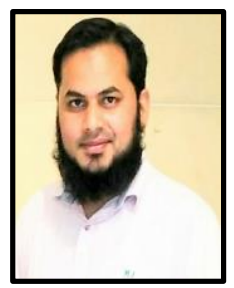

Dr. Mohd Tariq obtained his bachelor's degree in electrical engineering from Aligarh Muslim University, Aligarh, the master's degree in machine drives and power electronics from the Indian Institute of Technology (IIT)-Kharagpur and the Ph.D. degree from Nanyang Technological University (NTU), Singapore. He has worked as a Researcher at Rolls-Royce at NTU Corporate Laboratory, Singapore, where he has worked on the design and development of power converters for more electric aircraft. Before joining his Ph.D., he has worked as a scientist with the National Institute of Ocean Technology, Chennai under the Ministry of Earth Sciences, Government of India, where he has worked on the design and development of BLDC motors for underwater remotely operated vehicle application. He also served as an Assistant Professor with the Maulana Azad National Institute of Technology (MANIT), Bhopal, India. He is currently working as an Assistant Professor at Aligarh Muslim University wherein he is leading a team of multiple researchers in the domain of power converters, energy storage devices and their optimal control for electrified transportation and renewable energy application. He has authored more than 120 research articles in international journals/conferences including many articles in IEEE Transactions/Journals. He is also the founder chair of IEEE AMU Sb and founder chair of IEEE SIGHT AMU. 